\title{
Constructing the Scale of Faithful Personality Traits among the Students of Al al-Bayt University
}

\author{
Mohammad Olimat (Corresponding author) \\ Al al-Bayt University \\ Mafraq, Jordan
}

$\begin{array}{ccc}\text { Received: April 7, } 2014 & \text { Accepted: November 17, } 2014 \quad \text { Published: January 9, } 2015 \\ \text { doi:10.5296/ire.v3i1.6883 } & \text { URL: http://dx.doi.org/10.5296/ire.v3i1.6883 }\end{array}$

\begin{abstract}
This study aimed to build a measure of personality traits faith among university students, a random sample of the University students were selected and they were of (330) subjects, the researcher ensure the validity of the scale items through the indicators of paragraph correlation with total degree and the matrix of correlation coefficients between traits and factor analysis. Reliability of the scale was also ensured using Cronbach Alpha equation and re-test, and in midterm retail, and thus measure of faith personality traits among the students of the university was provided that can be trusted and used as a criterion in the selection of students who apply to study religious sciences.
\end{abstract}

Keywords: Scale, Personality, Faith, Trait

\section{Introduction}

There is an urgent need to exactly identify the personality approach, since it is very important to understand human behavior in various mental, psychological, social, physiological aspects, as well as discover the effectiveness of individual through accessing to proper interpretation of various mental phenomena (Karmian, 2007). The search in the scale of personality is one the most important researches that serves psychology, because of its importance to understand the analysis, components and hidden contents of personality as well as understand the treatment of diseases it faces (al sarkhi, 2002).

The contemporary psychologists neglected studying the spiritual side of individuals, and its impact on their characters and behaviors, and this led to a lack of understanding human's hidden contents and factors that determine the normal and abnormal personality (Nagaty, 2001). 
Scientific studies confirmed the superiority of Islamic teachings in terms of scientific side in preparing the faith personality; moreover conducting further studies and research will reveal the facts of faith in Allah and the beauty of the afterlife belief and how great is to follow the life of the Prophet Muhammad (AlSanea', 51419).

The Holly Quran presented a description of human personality and the features that distinguish human being, in addition to describe the normal and abnormal personality, and the factors consisting of both normality and abnormality in addition to determine the patterns of human personality in three patterns including a number of personality traits such like: faith personality, hypocritical personality and infidel personality (Melhem, 2002).

\section{$\underline{\text { Personality Scale }}$}

Although the scale of personality such as features, trends and tendencies is too late for measuring aspects of mental sides, (Rabee', 2008) and the diversity of theories that try to explain personality and its difference and disagreement on determining a specific concept of the character as well as the multiplicity of areas for those interested in studying it led to a difference in personality concepts that don't look the same for individual and others. Hence, it is a pattern of responses to external stimuli that can be possibly analyzed and scaled in spite of the personality unit (Ansari, 2000).

Thus, standards of personality scales advanced and evaluated in terms of quantitative and qualitative sides, which led to highly understanding of personality and the ability to be scaled more accurately than it was influenced by the evolution of building scales of personality as the psychologists encouraged the scales on one hand and applying them on the other hand (Qubaisi, 1987), and it has appeared several methods for personality scale including: scales, tests, observation, life record and case study. (Zubaie and others, 1981), where are the most of these methods that are commonly used in personality scale are scales and tests, and this is due to their ease of usage, besides they are highly valid and reliable (1977, Sundbergss).

Thus, the personality scales usually lie within the category of distinctive performance scales where there are no correct or wrong answers, but they concentrate on figuring out the individual differences in performance as it in academic achievement of tests, intelligence and capacity, so it depends on psychological scale (Psychometric), which is based on the scale of individual differences and comparing the degree of the individual among the scores of the Factor to which it belongs and these degrees of this Factor becomes a standard for judging the individual and determine the location for them.

\section{Measuring Religiosity}

The scale has spread over all areas of human life, moreover, the psychological scales were put in order to test the characteristics to be scaled in individuals and those characteristic of religiosity, as Western scientists have set standards of religiosity which are divided into three parts:

(1) The one-dimensional (unidimensional) scales which focused on measuring religiosity as a single dimension, and mostly focused on the trend towards the church or frequent attendance 
there, including the scale of (Thurston \& Chave, 1929), (Thoules, 1935) and the scale of religious values for All-Port and Vernon and Lindzey.

(2) The two-dimensional (Bipolar Dimensional) which focused on two dimensions of the religiosity scale such as (Proper and less desirable), (Good and bad), including the scale of (Lenski, 1961) and the scale of (Clark, 1958).

(3) The (multidimensional scale) which focused on different dimensions of religious behavior such as the scale of (Thouless, 1961), (Kurts, 1962), (Whiteman, 1961) and the scale of (A1 Sanee', 51419).

\subsection{Problem of the Study}

There is a scientific importance to make psychology compatible with Islamic postulates and assets, and what they offer to people in general and students in particular, the subject of scale in the psychology is one of the most important topics that put psychology in prestigious rank among people as a result of its concrete effects in different areas of life. The beginnings of psychometrics were with physical and mental aspects, personality traits, capacities and emotional and temperamental aspects. There is one side that was out of attention to study, which is the spiritual or religious aspect, and this is due to many reasons, the most importantly was the current point of view in the Western region regarding Islam religion (1992, Walff,) as a result the Muslims scale scientists were affected, where Western religion standards were translated and applied on Muslims (1978, Abu Nile), (1978, Hawari), (1959, Hana). And this problem needs to display the correct Islamic outlook to be scaled in different religion look from the Western society to suit the perspective of Islamic religiosity, and the value of the study can be affirmed through the following:

- Theoretical significance as the researcher seeks to demonstrate the importance of faith scale from Islamic perspective to a significant segment of society which is the university students.

- Applied importance represented in providing the scale of religiosity represented in the scale of faith personality traits among the students of the university where there are necessary psychometric characteristics, and it provides a scale tool suitable for researchers to use it in their scientific research, as the university students are considered as the largest segment of university. They are the base for making changes in various aspects of life, which requires careful planning to prepare them to future as well as exploit their energies to employ them well.

\subsection{Objective of the Study}

The objective of this study is to build a scale for faith personality traits among the students of the university.

\subsection{Definitions of Terms}

The Holly Quran: the words of Allah Almighty.

Al Emara (2005) also defined the personality: as the particular personality of an individual and a unique entity special to him holding qualities and characteristics which are different 
from the characteristic and qualities of others, in spite of the similarity of physical and mental creating.

The Scale: The scale is a quantization of how much a particular individual owns particular traits (Habib, 1996).

Faith: a commitment of the Muslim to the correct belief (faith in Allah and his angels, His Books, His Messengers, the Last Day, and the fate whether good or bad) and this appear on the behavior of individuals by doing the commands of allah and keep away from forbidden actions. Procedurally, the level of faith is defined as the total scores obtained by the student through his answers on the scale items of faith personality traits used in this study (Barhoum, 2009).

Trait: is the trait or genetic or acquired characteristic that are reliable and relatively distinguish individuals from each other, it is not directly noted by individuals but through certain indicators and actions, and it is considered as a principle to regulate some aspects of behavior to be predicted, (2006, Al Nadawy) and procedurally, it is known as the total degree obtained by individuals through answering items of faith personality traits.

\subsection{Limitation of the study}

The study was limited to a sample of students of Educational Sciences at Al al-Bayt University for the academic year 2012/2013.

\section{Previous studies}

The researcher benefited from previous studies which built a scale of key traits of personality aimed to build standards-related aspects of religion:

\subsection{Studies Aimed at Building Standards for Personality Traits Named after Them}

- Study of (Thurston \& Thurston, 1929) has built a scale of personality neuroticism among the students of the university, it was used the theory of factor analysis that combined the mental approach and experience approach in building the scale of personality, it was also used the interrogative phrases in composing the items of the scale as well as the options of answers which are (Yes, No, I do not know), the items were logically and statistically analyzed to be applied on a sample consisting of 649 individuals where it was used the correlation validity and the standards of percentage levels as well (Vernon, 1965).

The study conducted by (Radi, 1993) aimed at building a standardized scale of leading personality for students of a university in Iraq, this study adopted the traits theory of All port, this study combined the logical approach and experience in building the scale. This study identified (32) behavior components for leading personality, the items of the scale were formulated using the methods of verbal attitudes with three answers graded in their strength in the form of statements. The items of the scale were logically and statistically analyzed on a sample of 400 students by coefficient of honesty through a connection of items to the total score of scale. The reliability of the scale was verified through two indices which are reliability of content and reliability of construction. Whereas the validity was measured using 
the re-testing and split- half methods as well as equation of $(21$, Keodor - Richardson) and the percentage standards of the scale after applying it on a sample consisting of 3840 students. (Radi, 1993).

The study of (Araji, 1997) aimed to build a scale for challenging personality for students of the University in Baghdad, this study adopted the traits theory of Allport, it combined the logical approach and experience in construction. The study also identified (12) behavioral components, the items of the scale were set in the form of verbal attitudes, and every attitude has two answers. The items of the scale were logically and statistically analyzed after being applied on 530 students according to the distinguishing force using the Bacyrial correlation coefficient between the scores of each item as well as the total score of the scale, moreover, it was used the coefficient equation probability to verify the reliability of content and the construction, as for the validity of the scale, it was verified using the two methods of re-test, ANOVA analysis of variance as well as Hweit equation. (Araji, 1999).

The study of (Aldabaj, 1999) aimed at building a scale for mature personality for young students in a university in Iraq, the study adopted the traits theory of Allport, six traits were identified by combining the two approaches of experience and logic in building the scale, the items of the scale were composed using the reportage method with these options (always, often, Sometimes, rarely, never). The scale was applied on a sample of 600 students and the items were logically and statistically analyzed. The distinguishing force was verified by the correlation of items with the total score and the correlation coefficient was measured by using the equation of pattern probability, as for the reliability of the scale, it was measured by using the virtual reliability and reliability of construction, a as for the validity of the scale, it was verified using the two methods of re-test, ANOVA analysis of variance and the percentage standards were derived after being applied on (1200) students (1999, Aldbaj,).

Alrafoa, Q. (2003) conducted a study aimed at building a scale of independent personality among a sample of students of Applied University Faculty of Tafileh and make a survey of some factors affecting them, the original items set by Al Jawary (1998) were modified to absent format and it was used the four staging (strongly agree, agree, disagree, strongly disagree). The number of items of the scale was 30 items. The reliability of the scale was verified through indices of virtual reliability and the construction reliability, the degree of correlation for each one of the items were measured according to the total score. The reliability coefficient of the scale was figured out by using the Alpha Cronbach method by $87 \%$ and the test and re-test by $82 \%$.

\subsection{Studies Aimed at Building Metrics to Scale Some of the Religious Aspects:}

- A study conducted by Thurston and Chave, (1929) aimed at building the attitude scale towards the church. This scale consisted of 24 items distributed on moral, personal and social aspects linked to the church. (Shaw \& wright, 1967)

- A study conducted by Dyness, (1955) aimed at building the attitude scale towards the church and religious rituals among students depending the method of Likert who pointed to the religious rituals of the church (Shaw \& wright, 1967). 
- A Study conducted by (All port and Vernon and Lindzy, 1960) aimed to build a scale of values and one of the six dimensions was a scale of religious values (al sanee', 1419).

- A study conducted by (Taei, 1983) aimed at building a scale for religious behavior for the students of Kuwait University, the scale includes two objectives which are the religious belief and religious practice, it was used the method of reported phrases, two options to answer (yes, no) and the distinguishing force of items was scaled to verify the virtual validity and the correlated validity of the scale, and the reliability was scaled using the re-test method (Tai, 1983).

- Dagrasseh (Abdullah et al., 1991) aimed to build a scale of social values in Islam among students university in Jordan, which included scaling seven areas using the verbal positions, the items of the scale were logically and statistically analyzed after being applied on a sample consisting of (165) students. The distinguishing force was scaled by their correlation coefficient of total score. To verify the reliability of the scale, it was used Alpha Cronbach equation to make sure of the validity of the content as well as the distinguishing validity. (Abdullah et al., 1991)

- A study conducted by (Amin, 1996) aimed at building the scale of religious commitment to the students of the University of Baghdad in the light of the Islamic religion, it was used the reporting phrases which were logically statistically analyzed to scale the distinguishing force and its correlation coefficient with the total score. To verify the reliability of the scale, it was used the re-test and half-split methods then to verify the virtual validity.

- A study conducted by (Samarrai, 1999) aimed to build a scale of faith personality to sixth grade students in Iraq, this scale consisted of (14) behavioral components applied on a sample of (402) students. This scale was logically and statistically analyzed using indicators to the validity of content as well as validity of building the scale. To verify the reliability of the scale, it was used the method of re-test and analysis of variance.

- A study conducted by (Abu Nile \&Abdel Aal, 1987), who translated the scale of religious value of Allport and Vernon and Lendzy. The scale consisted of 30 questions and the sub scale, which measures the religious value, consisted of ten questions, each question has options, and it used in several studies but it was criticized as it is designed for non-Muslims. Another point it has few number of items which were only ten items. Moreover, Lack of options put for each question of the scale questions, where it scales the value of religious not religiousness.

- A study conducted by (Nassar, 1988), who built the scale of religious attitude, the scale consisted of (94) items, divided into three sections: the spiritual side which consists of (35) items composed in the form of a question and the second one is the behavioral side which consists of (34) items formulated in the form of behavioral position whereas the third side scales the cognitive aspect which also consists of (25) items. The options to answer the five are (always, often, sometimes, rarely, never), and the criticism on this scale was the overlap divisions and repetition in the items in addition to the lack of comprehensiveness in the various aspects of Islam. 
- The study conducted by (Al Sanee', 1419) that aimed to build a scale of religiosity consisted of 60 items with three options which are (one degree, two degrees, three degrees) the items of the scale covered the pillars of Faith, the pillars of Islam and the branches of faith. The reliability of the scale was measured by using the re-test method by (0.089) as well as the half-split method by (0.94). it was confirmed the validity of scale through two indicators: validity of arbitrators, and validity of internal consistency, and it was measured the degree of correlation between the degree of total scale and the degree of each item where 55 items were statistically significant at the level of 0.01 and five items are significant at the level of 0.05 .

\section{Methodology}

\subsection{Population of the Study}

The population of the study consisted of all the students of the Faculty of Educational Sciences for the year 2012/2013 at the Faculty of Educational Sciences at the University of Al al-Bayt. Their number was (1400) male and female students.

\subsection{Sample of the Study}

The researcher chose 6 people randomly from the students of the Faculty of Educational Sciences were chosen, and the number of respondents was (330) male and female students from different grade levels.

\subsection{Procedures of Building Scales}

Alpha Cronbach points to the need to determine the building concepts firstly which starts from procedures of building procedures of psychological scale as personality scales to start other procedural steps to build the scale (Alpha Cronbach, 1970).

\subsubsection{Determining the Traits of Faith Personality}

Firstly, the concept of faith personality was determined. The traits of faith personality were determined based on the theoretical framework and previous studies. This is through verses of the Holly Quran and Mohammedan hadiths where the number of sub-traits of the first one 16. After displaying these traits on specialists in the Islamic sciences, some of these traits were modified whereas three of them were merged to have at last 13 personality traits as shown in Table 1.

To determine the relative significance of each trait of faith personality, the specialists were asked to arrange these traits according to importance; each specialist gives a degree for every single trait from 13 to 1 . The most important trait takes the number of 13 whereas the less important takes number reaching to the least important one which takes number 1. 
Table 1. sub-trait of faith personality and the number of items in initial and final form

\begin{tabular}{llll}
\hline \multirow{2}{*}{ No. } & Sub-trait of faith personality & \multicolumn{2}{c}{ Number of items } \\
\cline { 3 - 4 } & & Initial & Final \\
\hline 1 & Believe in Allah & 10 & 9 \\
2 & Obedience to Allah & 10 & 9 \\
3 & Honesty & 8 & 7 \\
4 & Patience & 8 & 7 \\
5 & Obedience to parents & 8 & 7 \\
6 & Promotion of Virtue and Prevention of Vice. & 7 & \\
7 & Faithness & 7 & 6 \\
8 & Cooperation on goodness & 7 & 6 \\
9 & Respecting others & 7 & 6 \\
10 & Keeping away from forbidden & 7 & 6 \\
11 & Jihad & 7 & 6 \\
12 & Sacrifice and jihad in soul and money & 7 & 6 \\
13 & Good neighboring & 7 & 6 \\
& Total & 100 & 87 \\
\hline
\end{tabular}

\subsubsection{Setting the Items of the Scale}

The researcher prepared an initial form of the scale consisting of (100) items which is more than the required number for the final scale as determined according to the degree of importance of personality, distributed on the faith personality traits in anticipation of the excluding certain items when analyzed, to remain what covers the trait to be scaled.

The items were composed in the form of verbal positions using the self-report, and each position has two options to answer in the form of two phrases and the answers are (yes, no), these verbal positions were taken from faith personality traits, and the answers of the items were taken from a survey study conducted by the researcher. One more thing, the positions were composed in a specific paper to be presented to a sample of university students whose number was 100 students. These students were asked to answer each position of the scale. After completing all answers, they were analyzed to choose two answers for each position. One refers to a faith trait and the later does not; means it doesn't refer to a faith trait. The two answers were chosen from the repeated answers on each position to be formulated into two sentences as option $\mathrm{s}$ of the answer. When assessing, the option which scales the faith personality is given number 1 whereas the option that doesn't scale the faith personality is given (zero).

\subsection{Preparing Instructions for the Scale}

The objective of the scale was hidden in order not to affect the respondent. Cronbach point out that the explicit name of personality scale may make the respondent lies while answering. (Cronbach, 1970). It was pointed out in the instructions that items do not contain neither 
correct answers nor wrong ones, and that the respondent needs to choose the suitable option. Thus, the respondents were informed their responses will be kept confidential, and it will be used only for the purposes of scientific research.

- Correction of the scale:

Since each item of the scale contains two options, one of them represents the positive trait whereas the second represents the negative side of trait, thus it was given the two scores $(1$, zero) for these two options respectively.

- Logical analysis for the items of the scale by specialists:

In order to verify the validity of the items in the scale of faith personality traits, the items were displayed to (8) specialists in the religious sciences and psychometrics and educational scale, to assess the validity of items logically. Thus, according to their opinions, some of the items were modified for not receiving the approval of $80 \%$ from specialists; this percentage will be adopted to determine the validity of the items from the viewpoint of specialists. Moreover, the number of items that will be submitted to statistical analysis remained (100) items distributed on traits as shown in table (1).

- The clarity of the instructions to the respondents:

It was chosen the number of 50 students to apply the scale on them in order to make sure that instructions and items of the scale are clear and understood. It is permitted while answering the items from to ask about any ambiguity whether instructions or phrases or words, thus, it has been verified the clarity of instructions and readiness for the application, the application of the scale took (45) minutes of application, which is the sufficient time required to implement it.

\subsection{Reliability of the Scale}

We could figure out validity in the following ways:

The reliability is considered as one indicator to internal reliability and uniformity of the scale's items (Crocker \& Algine, 1986), and the purpose of measuring the reliability is evaluating the mistakes of the scale to suggest methods accordingly (Murphy, 1988).

\section{Alpha Cronbach method}

It is one of internal reliability method based on the links between the scores of the validity sample on all items of the scale. (Awdeh, 2000). The current reliability coefficient was measured in this way through the data obtained from the reliability sample, as it amounted to (89) which is a good reliability coefficient compared to the reliability scales regarding personality standards contained in previous studies.

- Method of test - retest

This test is considered one of the most common methods to measure the reliability coefficient, especially in the personality scales that illustrate the relative stability and reliability of personality over time. (Hassanein, 1995; 1997) and the scale of faith personality was applied 
on a sample of validity and reliability consisting of (101) individuals in the first time to be applied within two weeks later on the same sample, the scores in the two applications were measured using Pearson correlation coefficient between the scores of the two applications, the factor of (reliability) is equal to (87) which is good, because the value of reliable reliability coefficient in psychometric can preferably be more than (70) (Samurai, 1999).

The split-half method:

Scaling the reliability coefficient in this way is called the factor of internal consistency which is used in the tests and standards whose items are compatible. It scales a single psychological trait (Olimat, 2001). In this way, the items of the scale are divided after answering them into two parts (pair and single), where the pair items represent the first part of the scale, and single items represent the second part of the scale, and the correlation coefficient is scaled between the scores of the two parts. (1990,Imam and others). However, measuring the reliability of the test in this way, it represents half of the test, to be corrected using the equation of (SpermanBrown, 1972). As the faith personality traits of university students represent an integrated psychiatric trait as a whole, the researcher used this method to verify this assumption. Applying this way from the data of validity sample, it is clear that the correlation coefficient between the two halves of scale equal to (83); moreover, applying the equation of Sperman Brown, the reliability coefficient scale reached(91). Thus, the reliability coefficients which are extracted in various ways, are indicators that the scale is valid. Owdeh pointed out that (Mehrnz \& Lehman, 1980) confirm that the decisions that require the use of standardized tests should use coefficients at the least of (85), while they can less in personality standards (Owdeh, 2000).

\section{Standard error of the scale}

The standard error of scale expresses the standard deviation of a series of scales that were conducted (presumably) on the same individual. (Nunnaly, 1970) is also considered a proof of the scale accuracy, as it shows how close the degree of the individual to the scale of the real degree he obtained (Ebel, 1972). Thus, the standard error of scale was found through consistency coefficient of alpha Cornbach with the amount of (1.88).

\section{Results of the Study}

\subsection{Statistical Analysis of Items}

The process of statistical analysis of the items is considered a key step in the construction of any scale, to detect the psychometric traits of items that help select items with good traits which leads to increase the validity and reliability of the scale Anastasi, (1988) whereas Jezle, et al, (1981) confirmed this answer will find homogeneous sale free from impurities. It was used the total score of the scale as an internal touchstone in this analysis. Furthermore, this scale was applied on a sample consisting of (330) male and female students. Thus, the correlation coefficient ranged from 0.105 and 0.458

It was adopted in unveiling the validity of items of the scale, the duo correlation coefficient between the degree of each item (a scale of intermittent) and the total score of the scale (an 
ongoing scale). The specialists in psychological scale indicate that relationship high between the items and the total score of the scale means that the item scales the trait which is also scaled by the scale itself. Moreover, the exclusion of relevant items which have weak correlation with the total score or keeping the items which have good correlation makes the scale more homogeneous and valid, the internal consistency of items means that every single item aims to scale the same function that are scaled by the same study. So, the exclusion of relevant items which have weak correlation scale makes the study scale more valid. To achieve this, the correlation coefficient of each item was scaled with the total score of the scale of the sample data of statistical analysis whose number was (330) students, so that correlation coefficients ranged from $(0.105)$ and $(0.458)$.

In order to arrive at the final format of the scale, it was excluded the items with weak correlation which were (13) items, every one item for one trait, and thus the scale consisted of (87) items as shown in Table (1.2).

Table 2. The correlation coefficient of items with the total score of the scale of faith personality trait

\begin{tabular}{|l|l|l|l|l|l|l|l|l|l|}
\hline $\mathrm{N}$ & $\begin{array}{l}\text { correlation } \\
\text { coefficient }\end{array}$ & $\mathrm{N}$ & $\begin{array}{l}\text { correlation } \\
\text { coefficient }\end{array}$ & $\mathrm{N}$ & $\begin{array}{l}\text { correlation } \\
\text { coefficient }\end{array}$ & $\mathrm{N}$ & $\begin{array}{l}\text { correlation } \\
\text { coefficient }\end{array}$ & $\mathrm{N}$ & $\begin{array}{l}\text { correlation } \\
\text { coefficient }\end{array}$ \\
\hline & $* * 0.197$ & 19. & $* * 0.272$ & 37. & $* * 0.332$ & 55. & $* * 0.330$ & 73. & $* * 0.326$ \\
\hline & $* * 0.179$ & 20. & $* * 0.297$ & 38. & $* * 0.300$ & 56. & $* * 0.442$ & 74. & $* * 0.403$ \\
\hline & $* * 0.329$ & 21. & $* * 0.350$ & 39. & $* * 0.384$ & 57. & $* * 0.270$ & 75. & $* * 0.357$ \\
\hline & $* * 0.279$ & 22. & $* * 0.118$ & 40. & $* * 0.235$ & 58. & $* * 0.165$ & 76. & $* * 0.205$ \\
\hline & $* * 0.288$ & 23. & $* * 0.185$ & 41. & $* * 0.383$ & 59. & $* * 0.320$ & 77. & $* * 0.263$ \\
\hline & $* * 0.259$ & 24. & $* * 0.264$ & 42. & $* * 0.216$ & 60. & $* * 0.342$ & 78. & $* * 0.232$ \\
\hline & $* * 0.165$ & 25. & $* * 0.248$ & 43. & $* * 0.163$ & 61. & $* * 0.186$ & 79. & $* * 0.277$ \\
\hline & $* * 0.295$ & 26. & $* * 0.379$ & 44. & $* * 0.140$ & 62. & $* * 0.330$ & 80. & $* * 0.308$ \\
\hline & $* * 0.279$ & 27. & $* * 0.264$ & 45. & $* * 0.347$ & 63. & $* * 0.303$ & 81. & $* * 0.291$ \\
\hline & $* * 0.182$ & 28. & $* * 0.314$ & 46. & $* * 0.261$ & 64. & $* * 0.232$ & 82. & $* * 0.260$ \\
\hline & $* * 0.272$ & 29. & $* * 0.200$ & 47. & $* * 0.326$ & 65. & $* * 0.242$ & 83. & $* * 0.112$ \\
\hline & $* * 0.244$ & 30. & $* * 0.245$ & 48. & $* * 0.147$ & 66. & $* * 0.332$ & 84. & $* * 0.356$ \\
\hline & $* * 0.259$ & 31. & $* * 0.245$ & 49. & $* * 0.254$ & 67. & $* * 0.181$ & 85. & $* * 0.141$ \\
\hline & $* * 0.218$ & 32. & $* * 0.317$ & 50. & $* * 0.392$ & 68. & $* * 0.161$ & 86. & $* * 0.367$ \\
\hline & $* * 0.290$ & 33. & $* * 0.355$ & 51. & $* * 0.272$ & 69. & $* * 0.140$ & 87. & $* * 0.371$ \\
\hline & $* * 0.379$ & 34. & $* * 0.356$ & 52. & $* * 0.348$ & 70. & $* * 0.318$ & & \\
\hline & $* * 0.314$ & 35. & $* * 0.318$ & 53. & $* * 0.438$ & 71. & $* * 0.310$ & & \\
\hline & $* * 0.296$ & 36. & $* * 0.279$ & 54. & $* * 0.347$ & 72. & $* * 0.458$ & & \\
\hline
\end{tabular}

** Correlation at the level 0.01 .

* Correlation at the level 0.05 . 
It is clear from Table 2, which shows the correlation coefficients, that there are (82) items were statistically significant at the level $\alpha 0.01$ and that there are (5) items were statistically significant at the level of $\alpha 0.05$ and these items are Nos. $(23,44,57,83,85)$. Based on the above, that items scale of faith personality traits enjoys a high degree of honesty. (1988, Anstansi) indicated that the use of correlation items with the total score is considered a touchstone of internal indication to the validity of the scale in the absence of a, external touchstone. Accordingly, the researcher scaled the validity coefficient of the items by using Pearson correlation coefficient between the items and total scores which is considered an indicator to the validity of items (Anastansi, 1988; Omari, 2011).

Table 3. A matrix of correlation coefficients between the scale of faith personality traits for university students

\begin{tabular}{|l|l|l|l|l|l|l|l|l|l|l|l|l|l|}
\hline & 1. & 2. & 3. & 4. & 5. & 6. & 7. & 8. & 9. & 10. & 11. & 12. & 13. \\
\hline 1. & & & & & & & & & & & & \\
\hline 2. & $* * 0.196$ & & & & & & & & & & & \\
\hline 3. & $* * 0.209$ & $* * 0.197$ & & & & & & & & & & & \\
\hline 4. & $* * 0.221$ & $* * 0.373$ & $* * 0.338$ & & & & & & & & & & \\
\hline 5. & $* * 0.174$ & 0.048 & $* * 0.145$ & $* * 0.206$ & & & & & & & & & \\
\hline 6. & $* * 0.181$ & $* * 0.263$ & 0.068 & $* * 0.340$ & 0.074 & & & & & & & & \\
\hline 7. & 0.053 & $* * 0.066$ & $* * 0.198$ & $* * 0.305$ & 0.103 & $* * 0.180$ & & & & & & & \\
\hline 8. & 0.054 & $* * 0.216$ & $* * 0.201$ & $* * 0.342$ & 0.054 & $* * 0.179$ & 0.115 & & & & & & \\
\hline 9. & 0.053 & $* * 0.205$ & $* * 0.191$ & $* * 0.202$ & 0.056 & $* * 0.193$ & 0.121 & 0.132 & & & & & \\
\hline 10. & 0.052 & $* * 0.176$ & $* * 0.182$ & $* * 0.193$ & 0.053 & $* * 0.176$ & 0.118 & 0.122 & 0.132 & & & & \\
\hline 11. & 0.049 & $* * 0.182$ & $* * 0.179$ & $* * 0.182$ & 0.054 & $* * 0.186$ & 0.108 & 0.119 & 0.127 & 0.115 & & & \\
\hline 12. & 0.051 & $* * 0.196$ & $* * 0.184$ & $* * 0.177$ & 0.052 & $* * 0.179$ & 0.111 & 0.121 & 0.117 & 0.105 & 0.109 & & \\
\hline 13. & 0.049 & $* * 0.181$ & $* * 0.177$ & $* * 0.183$ & 0.055 & $* * 0.187$ & 0.101 & 0.117 & 0.124 & 0.108 & 0.102 & 0.107 & \\
\hline
\end{tabular}

The validity of the scale was verified through a construction matrix of internal correlations among the thirteen traits, and this is through the validity and reliability of the sample's degrees which were (101) individuals out of the statistical analysis sample, using the Pearson correlation coefficient as shown in Table 3.

The correlation of items with the total score of the scale indicates that items scale the same concept which is scaled by the scale of 1972, Stanley and Hopkins. The validity of the scale depends on how much we get information on the traits to be scaled, and this is done by knowing saturation test of the factor to be scaled (Awadallah, 2000). And therefore, the analysis factor uses another way to verify the validity of the scale and tests. On this basis, it was verified the validity of the scale pertaining the faith personality traits among university students by the following indicators: has been verified the veracity of building scale faith personality traits for university students through the following indicators:

(1) Excluding items with weak validity (discrimination) of the scale. 
(2) Measuring the correlation coefficients of the traits matrix.

(3) Conducting the factor analysis.

\subsubsection{Factor analysis}

The valid factor is considered one of the most accurate and powerful to notice the validity of the scale, it is designed to detect common factors that affect in any number of different phenomena, through the disappearance of multi phenomena by being analyzed to fewer factors, since it is heading for a rigorous scientific brief (Olimat, 2001). The valid factor depends on how much we can get information about traits to be scaled. it can be verified by applying the method of factor analysis to determine the extent of items saturation which is scaled by (Essawi, 1985). Thus, the application of this scale in the current research, (101) answer sheets were submitted to the factor analysis using the basic components method. It was used the (Principle component matrix) in the analysis, which showed (36) factors before rotating.

To determine the variables (items) whose degrees of saturation were statistically significant, it was used Kaiser method which indicates that the amount of saturation acceptable to determine the factors is more than 0.30 (Samadi, 2009) and based on the least determinant of Cuttmans which determines the significant factor through the underlying root which can be explained, and which is equal to or more than (1) integer (Abdel-Khaleq, 1983) the value of the underlying root ranged from (8.869) and (1.004), as shown in Table 4.

Table (4). The underlying root percentage of unexplained variation by each worker before recycling

\begin{tabular}{|l|l|l|l|l|l|l|l|}
\hline Number & $\begin{array}{l}\text { underlying } \\
\text { root }\end{array}$ & $\begin{array}{l}\text { percentage of } \\
\text { interpreter } \\
\text { variance }\end{array}$ & $\begin{array}{l}\text { percentage of } \\
\text { total interpreter } \\
\text { variance }\end{array}$ & number & $\begin{array}{l}\text { underlying } \\
\text { root }\end{array}$ & $\begin{array}{l}\text { percentage of } \\
\text { interpreter } \\
\text { variance }\end{array}$ & $\begin{array}{l}\text { percentage } \\
\text { total } \\
\text { interpreter } \\
\text { variance }\end{array}$ \\
\hline 1. & 8.869 & 8.869 & 8.869 & 20. & 1.406 & 1.406 & 48.21 \\
\hline 2. & 4.733 & 4.733 & 13.601 & 21. & 1.371 & 1.371 & 49.393 \\
\hline 3. & 3.414 & 3.414 & 17.015 & 22. & 1.353 & 1.353 & 50.745 \\
\hline 4. & 2.540 & 2.540 & 19.554 & 23. & 1.330 & 1.330 & 52.075 \\
\hline 5. & 2.279 & 2.279 & 21.833 & 24. & 1.307 & 1.307 & 53.382 \\
\hline 6. & 2.196 & 2.196 & 24.029 & 25. & 1.275 & 1.275 & 54.658 \\
\hline 7. & 2.116 & 2.116 & 26.145 & 26. & 1.239 & 1.239 & 55.896 \\
\hline 8. & 2.036 & 2.036 & 28.181 & 27. & 1.217 & 1.217 & 57.113 \\
\hline 9. & 1.892 & 1.892 & 30.073 & 28. & 1.206 & 1.206 & 58.320 \\
\hline 10. & 1.832 & 1.832 & 31.905 & 29. & 1.191 & 1.191 & 59.511 \\
\hline 11. & 1.791 & 1.791 & 33.696 & 30. & 1.161 & 1.161 & 60.672 \\
\hline 12. & 1.748 & 1.748 & 35.445 & 31. & 1.118 & 1.118 & 61.790 \\
\hline 13. & 1.732 & 1.732 & 37.177 & 32. & 1.104 & 1.104 & 62.893 \\
\hline 14. & 1.694 & 1.694 & 38.871 & 33. & 1.075 & 1.075 & 63.969 \\
\hline 15. & 1.645 & 1.645 & 40.516 & 34. & 1.057 & 1.057 & 65.062 \\
\hline 16. & 1.596 & 1.596 & 42.112 & 35. & 1.051 & 1.051 & 66.077 \\
\hline 17. & 1.554 & 1.554 & 43.666 & 36. & 1.004 & 1.004 & 67.081 \\
\hline 18. & 1.509 & 1.509 & 45.175 & & & & \\
\hline 19. & 1.441 & 1.441 & 46.606 & & & & \\
\hline
\end{tabular}


According to the wide dispersion shown by the percentage of interpreter variation in table (4) For the purpose of simplification and clarity, it was conducted the analysis of rotated factor matrix of Kaiser since it leads to the most appropriate solutions which complete the characteristics of simple construction (Faraj, 1991). The results of rotated factor matrix showed that there are (36) factors distributed on saturation of items.

It turns out there is variation in the items whose saturation is statistically significant and the percentage of .30 or above. it seems from this that faith personality reflects a central, basic and overlapping trait with its subsidiary components, the first factor sutured with a large proportion of items, which accounted a large number of faith personality traits.

To verify how factors represent traits, the scale was analyzed using the rotated factor matrix of the Eight method. The results of rotated factor matrix showed a simple interpretation to the factors of faith personality traits as shown in the current scale. The eight traits were interpreted with the increase of underlying root in interpreting the eight traits that became (2.036) as well as increasing the saturation which was at the level of (0.040). Accordingly, the items representing every a trait in the Eight factor analysis appeared as shown in Table 5.

Table 5. Factor analysis approach to eight items of personality faith Scale

\begin{tabular}{|l|l|l|l|l|l|l|l|l|l|l|l|l|l|l|}
\hline number & 37 & 33 & 39 & 40 & 38 & 34 & 27 & 42 & 35 & 28 & 36 & 29 & 26 & 31 \\
\hline & 0.68 & 0.67 & 0.65 & 0.64 & 0.63 & 0.60 & 0.56 & 0.55 & 0.53 & 0.50 & 0.46 & 0.45 & 0.44 & 0.43 \\
\hline
\end{tabular}

2- Second factor

\begin{tabular}{|l|l|l|l|l|l|l|l|l|l|l|l|l|l|l|l|l|l|}
\hline number & 3 & 53 & 66 & 68 & 67 & 78 & 57 & 4 & 52 & 20 & 69 & 2 & 10 & 61 & 84 & 1 & 63 \\
\hline & 0.49 & 0.48 & 0.46 & 0.46 & 0.44 & 0.43 & 0.43 & 0.41 & 0.42 & 0.40 & 0.40 & 0.41 & 0.40 & 0.44 & 0.45 & 0.42 & 0.41 \\
\hline
\end{tabular}

3- Third factor

\begin{tabular}{|l|l|l|l|l|l|l|l|l|l|l|l|l|l|}
\hline Number & 16 & 9 & 64 & 24 & 60 & 13 & 87 & 2 & 82 & 18 & 59 & 46 & 45 \\
\hline & 0.46 & 0.45 & 0.43 & 0.44 & 0.42 & 0.41 & 0.41 & 0.40 & 0.43 & 0.42 & 0.41 & 0.41 & 0.40 \\
\hline
\end{tabular}

4- Fourth factor

\begin{tabular}{|l|l|l|l|l|l|l|l|}
\hline number & 73 & 72 & 71 & 74 & 85 & 79 & 8 \\
\hline & 0.63 & 0.59 & 0.58 & 0.75 & 0.46 & 0.42 & 0.40 \\
\hline
\end{tabular}

5- Fifth factor

\begin{tabular}{|l|l|l|l|l|l|l|l|}
\hline number & 47 & 80 & 58 & 62 & 43 & 70 & 75 \\
\hline & 0.45 & 0.44 & 0.42 & 0.41 & 0.41 & 0.40 & 0.40 \\
\hline
\end{tabular}

6- Sixth factor

\begin{tabular}{|l|l|l|l|l|l|l|}
\hline Number & 6 & 5 & 7 & 12 & 11 & 49 \\
\hline & 0.64 & 0.63 & 0.47 & 0.43 & 0.41 & 0.40 \\
\hline
\end{tabular}

7- Seventh factor

\begin{tabular}{|l|l|l|l|l|l|l|l|}
\hline number & 54 & 67 & 55 & 65 & 56 & 51 & 15 \\
\hline & 0.48 & 0.41 & 0.40 & 0.41 & 0.42 & 0.40 & 0.40 \\
\hline
\end{tabular}


8) Eigth factor:

\begin{tabular}{|l|l|l|}
\hline Number & 19 & 14 \\
\hline & 0.40 & 0.41 \\
\hline
\end{tabular}

Factor I: it was interpreted as the factor of (faith in Allah) due to the presence of high positive branching belongs to the following items $(37,33,39,40,38.34,27,42,35,28.36,29,26,31)$, according to the test adopted by the researcher to identify the factors which is 0.40 or more, and the number of branching items were (14) items as described in Table 5.

Factor II: it is interpreted as the factor of (obedience to Allah to perform the obligatory prayers) and this is due to the presence of positive branching concerning the following items $(3,53,66,68,67,78.57,4,52.20,69,2,10,61,84,63)$ the number of branching items was (17) as shown in Table 5.

Factor III: it is interpreted as the factor of (devotion to duty) to the presence of high positive branching belong to the following items $(16,9,64.60,13,78.2,82,18.59,46,45)$ and the number of branching items was (13) as shown in Table 5 .

Factor IV: it is interpreted as the factor of (cooperation on charitable work) due to the presence of high positive branching belong to the following items $(73,72,71.74,85,79.8)$ and the number of branching items was (7), as shown in Table 5.

Factor V: it is interpreted as the factor of (patience) and this due to the presence of high positive branching belong to the following items $(47.80,58,62.43,70$, and 75$)$ and the number of branching items was (7), as shown in Table 5.

Factor VI : it is interpreted as the factor of (thinking in Allah's creatures) due to the presence of high positive branching belong to the following items $(5,6,7,12,11,49)$ and the number of branching items was (6), as shown in Table 5.

Factor VII: it is interpreted as the factor of (jihad and willingness to sacrifice) and this due to the presence of high positive branching belong to the following items $(54.67,55,65.56,51$, 25 ) and the number of branching items was (7) items, as shown in Table 5.

Factor VIII: it is interpreted as the factor of (workmanship for the performance of duty) and this due to the presence of high positive branching concerning the following items $(19,14)$ and the number of branching items was (2) as it is shown in Table 5.

Table 6. The variance percentage interpreting the eighth factors in the eighth factor analysis

\begin{tabular}{|l|l|l|}
\hline Number & Name & \\
\hline 1. & Believe in Allah & 8.869 \\
\hline 2. & Obedience to Allah by performing obligations & 4.733 \\
\hline 3. & Sincerity in work & 3.414 \\
\hline 4. & Cooperation on charity & 2.540 \\
\hline 5. & Patience & 2.279 \\
\hline 6. & Thinking in Allah's creatures & 2.196 \\
\hline 7. & Jihad and sacrifice & 2.116 \\
\hline 8. & workmanship for the performance of duty & 2.036 \\
\hline Total & & 28.181 \\
\hline
\end{tabular}


In this way the Eight factor analysis interpreted about (28.181) of the variance among individuals of validity and reliability sample,

The largest share was in favor of the factor of believe in Allah which interpreted nearly (8.869) out of (28.181) as seen from the table above, obedience to Allah to perform the obligatory prayers was ranked the second factor, which interpreted about (4.733) of the variance, whereas the third rank was the factor of sincerity in performing the duty, which interpreted about (3.414) of the variance. As for the factor of cooperation for goodness, it came in the fourth rank which interpreted about (2.540) of the variance, whereas the fifth rank was for the factor of patience which interpreted $(2,279)$ of the variance. Moreover, the factor of thinking in Allah's creatures came in the sixth rank which interpreted about (2.196) of the variance, and as for the seventh rank, it was for the factor jihad and willingness to sacrifice, which interpreted nearly (2.116) of the variance. Finally, the eighth rank went for the factor of workmanship to perform duties, which interpreted about (2.036) of the variance.

To measure the reliability coefficients of faith personality traits factors through measuring the means of branching significance as shown in Table 7 for each one of the eight factors, and this level has adopted an indication for the reliability of the scale.

Table 7. The reliability coefficients of faith personality traits factors for university students

\begin{tabular}{|l|l|l|}
\hline $\begin{array}{l}\text { Scale of personality traits for } \\
\text { university students }\end{array}$ & Factors of the scale & $\begin{array}{l}\text { The means of significant } \\
\text { branching }\end{array}$ \\
\hline & Believe in Allah & 55.64 \\
\hline & $\begin{array}{l}\text { Obedience to Allah by } \\
\text { performing obligations }\end{array}$ & 43.23 \\
\hline & Sincerity in work 4 & 42.23 \\
\hline & Cooperation on charity & 52.14 \\
\hline & Patience & 41.85 \\
\hline & Thinking in Allah's creatures & 49.66 \\
\hline & Jihad and sacrifice & 53.28 \\
\hline & $\begin{array}{l}\text { workmanship for the } \\
\text { performance of duty }\end{array}$ & 40.5 \\
\hline
\end{tabular}

\subsection{Conclusion}

A scale for personality traits faith among university students was built according to Bort theory of traits, the availability of psychometric properties in the scale were verified through the implications of validity indicators of item correlation with the total degree. and matrix coefficients, and by using factor analysis, as it was possible to identify eight traits that the form the scale in its final version, reliability was calculated using the Cronbach alpha reliability coefficient, which stood at 89 . And by using re-test it was 87 , by using retail midterm it reached 91. Delegation explained the eight factor analysis accounted for 181. 28 members of the contrast between the sample validity and reliability, saturation standard for the paragraph was adopted and accounted for 40 or above and thus resulting arranging 
features; first: Faith in God and it consisted of (14) paragraphs, and the saturation standard was limited between 43-68. The second feature was: God Obedience and it consisted of 17 paragraphs; the saturation standard was limited between 41-49. The third feature was devotion to duty and it consisted of 13 paragraphs, the saturation standard was limited between $40-49$ as well as the rest of the features.

And thus a scale of personality traits faith for college students was provided and can be relied upon and used in the selection of the touchstone additional students who are studying the religious sciences, which can be benefit from by the owners of competence in the educational process.

\subsection{Recommendations}

- Using a scale of faith personality traits for university students, an additional course in selecting students who are studying the religious sciences.

- We can take advantage of standard components (basic traits) in the preparation of programs for students to increase their faith.

- Using a scale of faith personality traits for choosing religious science teachers.

\subsection{Suggestions}

- Building a scale of faith personality traits for students of unions in universities.

- Develop the current scale through the preparation of sub- standards, according to the main traits that resulted from the eight factor analysis procedures.

- A study to detect differences in the faith personality traits among students in various scientific disciplines.

\section{References}

The Holly Quran.

Abdel, K. A. (1983) Personality Intelligence, 2nd Floor, Alexandria, House of University Knowledge.

Abdel, L. A., Abdul, R. S., \& Anwar, R. (1990). Personality traits and the ability to innovative thinking among a sample of adolescents twins and children, research on Sixth Annual Conference of Psychology in Egypt, the first part. The Egyptian Association for Studies.

Abdullah, et al. (1991). Building a scale of social values in Islam, Jordan. Muta Journal of Research and Studies, a series of Humanities and Social Sciences, 6(3).

Abu Nile, S. M. (1980). Psychological Statistics and Social Council (applied field research) i 3, Cairo, Khanji Library.

Aldbaj, N. (1999). Building a mature personality scale of Undergraduate Students, Unpublished Master Thesis, University of Baghdad, faculty of Education, Ibn Rushd.

Allam, S. (1986). Contemporary developments in psychological and educational scale, 
Kuwait, Commercial Printing Qabas.

All port, G. (1961). Parbern and Growth in personality, New York, Holt,Rinehart and, Winston.

Alrafoa, M. (2003). Scale of exploitative personality in a sample of students in Tafila Applied University College, and to explore some of the factors. Damascus University Journal Volume 12(1).

Al Sanee, S. (1419). Religiosity treatment of crime, Riyadh, adulthood library, i 2 .

Al Sarkhi, I. (2002). behavior and character - building between Western theories and between the Islamic perspectives.

Amin Abdul, H. (1996). Religious commitment and its relationship to psychological compatibility among students of the University of Baghdad, Unpublished Master Thesis, University of Baghdad, Faculty of Arts.

Ansari, A. (2000). Scale of personality, Kuwait University, Dar talking book.

Araji, I. (1997). building personality scale challenging for the students of the University of Baghdad, Unpublished Master Thesis, University of Baghdad, College of Education, Ibn Rushd.

Ashqar, Omar Suleiman. (1989). Belief in Allah, Kuwait, Al Falah library for publication and distribution.

Astasi, A. (1988). Psychological Testing New York, Macmillan.

Attiya, H. (2001). Experimental study of compared values (p. 1). Cairo, World Press.

Awadallah, M. (2000). Comparison between techniques model and the traditional way of building intelligence tests using the test to predict academic achievement, unpublished Ph.D. dissertation, University of Baghdad, College of Ibn Rushd.

Barhoum, A. (2009). The role of the teacher in the promotion of the values of faith among secondary school students in the cities of Khan Yunis, Gaza from the point of view of the students, unpublished Master, the Islamic University of Gaza, the College of Education.

Brown, F. (1983). Principles of Educational and Psychological Testing, New York, Holt, Rinehart and Winston.

Cronbach, L., \& Gleser, G. (1970). Essentials of psychological testing (3nd ed.). New York: Harper and Row.

Crocker, L., \& Algine, G. (1986). Introduction to classical and modern Test Theory. New York, CBS college publishing .

Ebel, R. (1972). Essentials of Educational Measurement (2nd ed.). New York: Prentice Hall.

Eisaws, A. (1985). Scale and experimentation in psychology and education of Alexandria, knowledge House. 
Emara, S. (2005). Anxiety and stomach ulcers, the dialogue spokesman web site number 1292.

Faraj, S. (1991). Factor analysis in the behavioral sciences. Cairo, Arab Thought House, 2nd $\mathrm{Fl}$.

Ghiselli et al. (1981). Measurement theory For Behavioral Sciences m San Fran Ciesco. W, H Freeman and Compang.

Hassanein, M. (1995). Scale and Evaluation in Physical Education, Cairo, House of Arab Thought for printing and publishing, i 3, C 1.

Hawari, M. (1978). religiosity and psychological adjustment, psychology seminar on Islam, Riyadh, Riyadh University.

Mam, M. (1990). Evaluation and scale, House of Wisdom.

Karmian, S. (2007). Personality traits and their relationship with concern the future of the employees on a temporary basis from the Iraqi community in Australia, a doctoral thesis of educational psychology, Arab Open Academy in Denmark.

Kenkel, W. (1980). Society in Action Introduction to Sociology. New York 2nd Harper.

Kubaisi, K. (1987). Building a personality scale rationing priority in admission to military colleges among students in the sixth grade intermediate in Iraq, unpublished Ph.D. dissertation, University of Baghdad, College of Education Ibn Rushd.

Magdi, H. (1996). Evaluation and scale in education and psychology, Cairo, the Egyptian Alnahda library, i.

Melhem, S. (2002). The problems of a kindergarten child, Oman Fikr House, i 1.

Murphy, R. (1988). Psychological testing Principles and application. New York, All international, Inc.

Nadawy, A. (2006). Changing personality and professional relationship compatibility among workers in state institutions, Unpublished Master Thesis, Faculty of Arts, University of Baghdad.

Najati, M. (2001). Introduction to Islamic Psychology, Dar El Shorouk, Cairo, Egypt.

Nassar, A. (1988). some of the personality and social variables related to religious attitude, unpublished Ph.D. thesis, Mansoura University, College of Education.

Olimat M. (2001). Building scale personality traits of leadership for managers working in Jordan, unpublished Ph.D. dissertation, University of Baghdad, College of Education Ibn Rushd.

Omari, H. (2011). the impact of ordering items in the psychological scales in the internal reliability of the scale and characteristics of its items. Damascus University Journal, $27(3 \& 4)$. 


\section{Macrothink}

International Research in Education

ISSN 2327-5499

2015, Vol. 3, No. 1

Rabee, M. (2008). Scale of personality, Jordan, Dar Al Masirah for publication and distribution.

Radi, A. (1993). To build a standardized scale of leadership personality for university students, the University of Baghdad, faculty of Education Ibn Rushd.

Samurai, M. (1999). To build a faith personality scale of sixth grade students in Iraq, Unpublished Master Thesis, University of Baghdad, Faculty of Education Ibn Rushd.

Saleh, Q. (1988.) Personality among scale, Baghdad, Higher Education Press and scientific research.

Shaw, M., \& Wright, J. (1967). Scales of measurement of attitudes. New York: McGrow-Hill.

Smadi, A., \& Abu Nawash, A. (2009). Dimensional components of traits between factor arbitration and analysis. Damascus University Journal, 25(3\&4).

Sundberg, N. (1977). Assessment of person. New gersey, Prentice- Hall.

Taei, N. (1983). A scale of religious behavior, Kuwait, Kuwait University, Rubaiaan company for publication and distribution.

Vernon, P. (1965). Personality test and Assessment. London: Methuen and Co. Ltd.

Wiggins, J. (1973). Personality and Predication: Principles of Personality Assessment, California: Addison Wesly.

Wolf, D. (1996). Good Measures: Assessment as a Tool for Educational Reform. Educational Leadership, 49(8), 8-13.

Zebari, S. (1997). the psychometric characteristics of the two attitudes of verbal declarative phrases in building personality standards, unpublished Ph.D. dissertation, University of Baghdad, Faculty of Education, Ibn Rushd.

Zobaie et al. (1981). Psychological tests and scales of Mosul University, printing and publishing house.

\section{Copyright Disclaimer}

Copyright reserved by the authors.

This article is an open-access article distributed under the terms and conditions of the Creative Commons Attribution license (http://creativecommons.org/licenses/by/3.0/). 